\title{
Comparison of Pregnancy Rate of Frozen Embryos Using Two Methods of long with GnRH Agonist and OCP with Estradiol Only
}

\author{
Soghra Rabiei ${ }^{1}$,* (D), Mohammad Fallah ${ }^{2}$, Fatemeh Jamshidi ${ }^{3}$ \\ ${ }^{1}$ Professor, Department of Obstetrics and Gynecology, School of Medicine, Hamadan University of Medical Sciences, \\ Hamadan, Iran \\ 2 Professor, Department of Parasitology and Mycology, School of Medicine, Hamadan University of Medical Sciences, \\ Hamadan, Iran \\ ${ }^{3}$ Resident, Department of Obstetrics and Gynecology, School of Medicine, Hamadan University of Medical Sciences, \\ Hamadan, Iran \\ * Corresponding Author: Soghra Rabiei, Department of Obstetrics and Gynecology, School of Medicine, Hamadan University \\ of Medical Sciences, Hamadan, Iran.Email: rabiei@umsha.ac.ir
}

Received: 25.12 .2019

Accepted: 14.04 .2020

How to Cite this Article:

Rabiei S, Fallah M, Jamshidi F. Comparison of Pregnancy Rate of Frozen Embryos Using Two Methods of long with GnRH Agonist and OCP with Estradiol Only. Avicenna $J$ Clin Med. 2020; 27(1): 5-12. DOI: 10.29252/ajcm.27.1.5

\section{Abstract}

Background and Objective: The management method of the luteal phase in the treatment of infertility is controversial, and there is no general agreement regarding the preferred protocol. The purpose of this study was to compare the pregnancy rate of frozen embryos in the long method with the gonadotropin-releasing hormone $(\mathrm{GnRH})$ agonist and oral contraceptives (OCP) with estradiol alone.

Materials and Methods: In this clinical trial study, a total of 128 in vitro fertilization candidates were randomly assigned into two groups of receiving $64 \mathrm{GnRH}-\mathrm{OCP}$ agonists (group A) and estradiol alone (group B). In group A, 15 days after menses, the patients received OCP for 12 days, and GnRH agonists were also given for 14 days. In group B, 6-mg estradiol valerate tablets were used twice a day for 5 days, in case of normal endometrial thickness for at least 10 days. Then, the consequences of the intervention were compared between the two groups.

Results: According to the obtained results, the study groups were similar regarding mean age and duration, type, and cause of infertility ( $\mathrm{P}>0.05)$, and there was no significant difference in this regard. The mean of taken eggs, formed embryos, and transferred embryos were similar in terms of the number, motility, and morphology of the spermatozoa. The frequency rates of laboratory and clinical pregnancies were $17.2 \%$ and $15.6 \%$ as well as $23.4 \%$ and $20.3 \%$ in groups $\mathrm{A}$ and $\mathrm{B}$, respectively ( $\mathrm{P}>0.05)$. The rates of abortion and multiple pregnancies were $1.6 \%$ and $3.1 \%$ in groups $\mathrm{A}$ and $\mathrm{B}$, respectively $(\mathrm{P}>0.05)$.

Conclusion: The pregnancy rates of frozen embryos in the long method with GnRH agonist and OCP with only estradiol were not reported with a significant difference regarding pregnancy outcomes.

Keywords: Estradiol, Frozen Embryo, GnRH Agonist 
بررسى مقايسهاى ميزان باردارى جنينهاى فريزشده در روش long با آكونيست GnRH

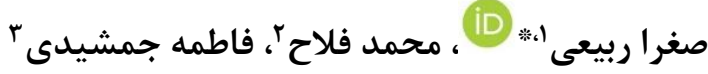 \\ ' استاد، گروه جراحى زنان و زايمان، دانشكده يزشكى، دانشخاه علوم يزشكى همدان، همدان، ايران

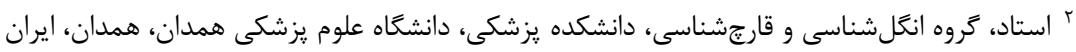

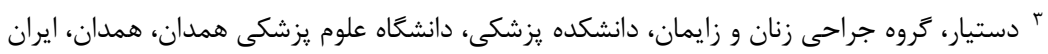 \\ إث نويسنده مسئول: صغرا ربيعى، گروه جراحى زنان و زايمان، دانشكده يزشكى، دانشكاه علوم يزشكى همدان، همدان، ايران.
} ايميل:umsha.ac.ir

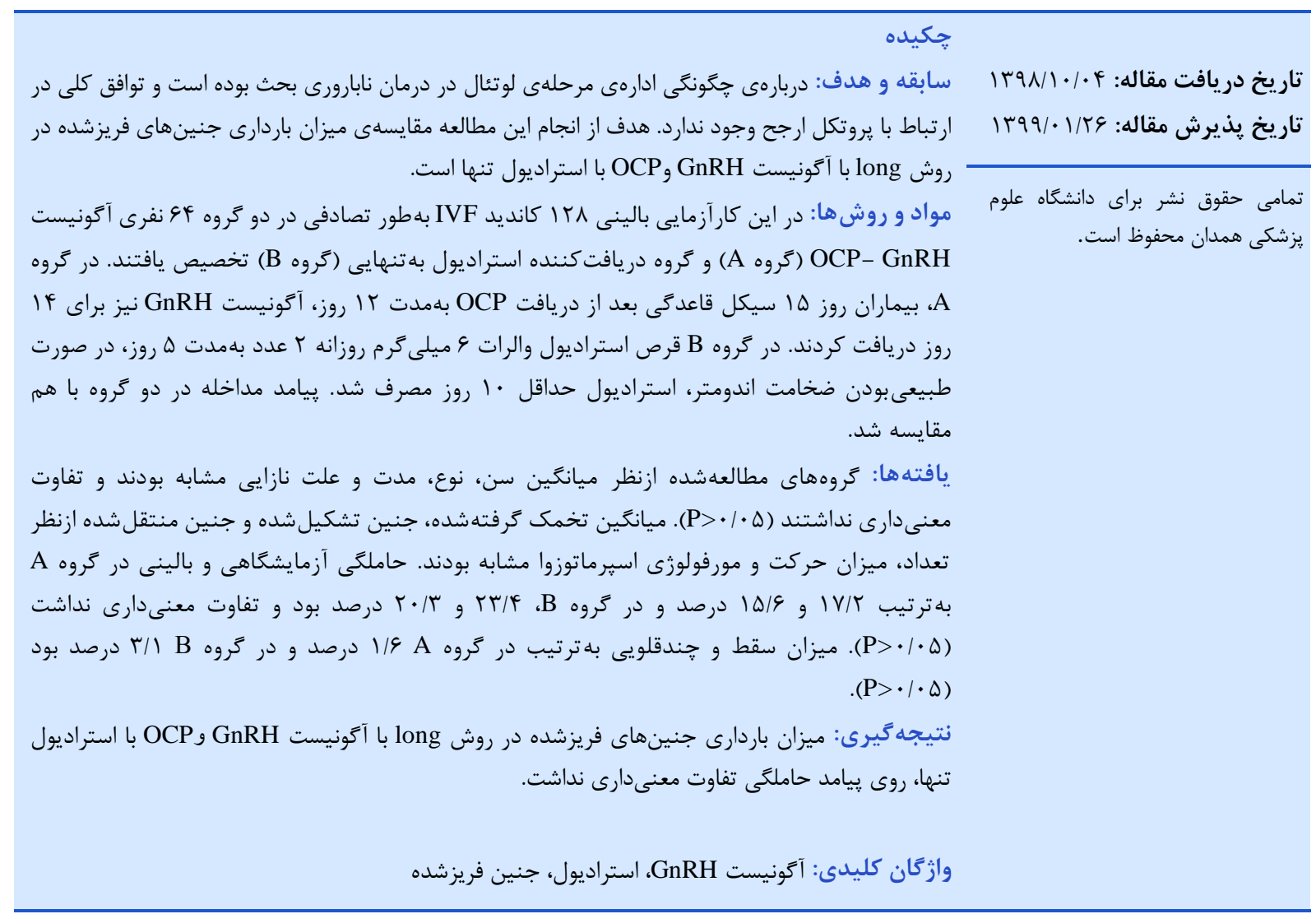

بعدى استفاده كرد. احتمال حاملكى فرد با استفاده از جند نوبت

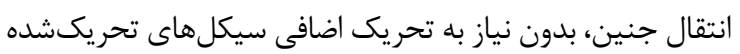
افزايش مىيابد [ب]

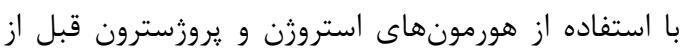

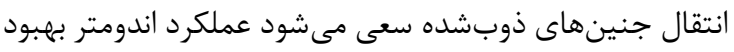

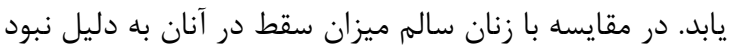

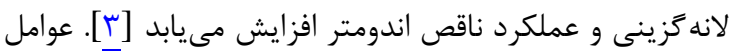
مختلفى سبب تغيير نتيجهى درمان زوجين نازا بهدنبال كاربرد
با ي يشرفت فناورى يكى از روشهاى معرفىشده در درمان

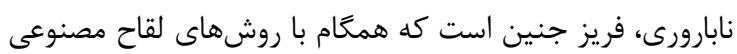

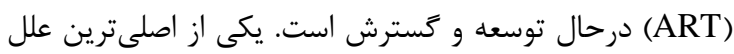
توسعهى روشهاى فريز و انتقال رويان فريزشده، كاهش خطر تورئر

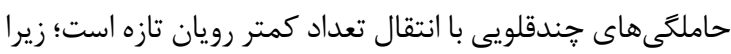

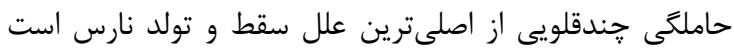

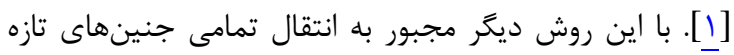

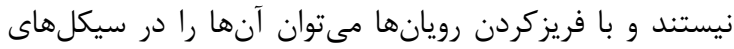


جنين فريزشده افزايش مى ائهد [9].

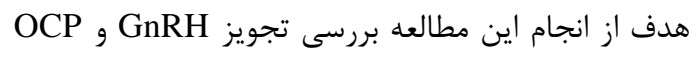

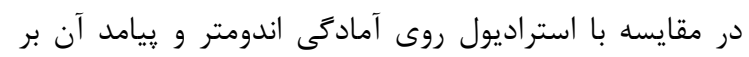

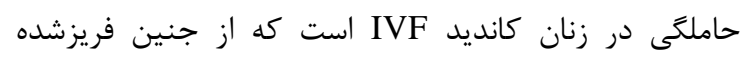

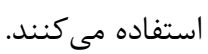

\section{مواد و روشها}

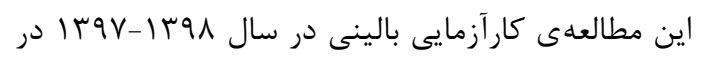

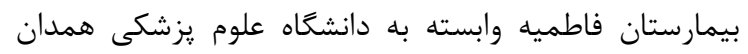

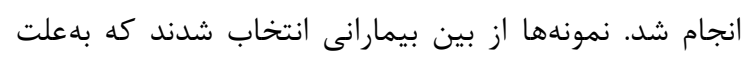

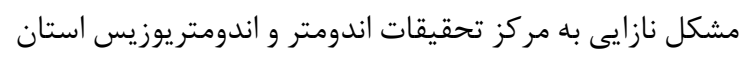

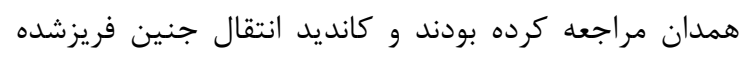

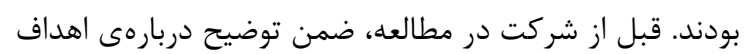

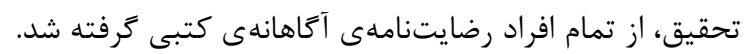

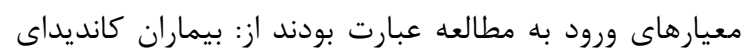

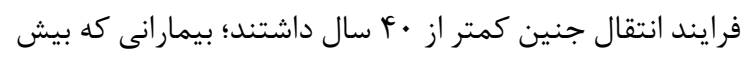

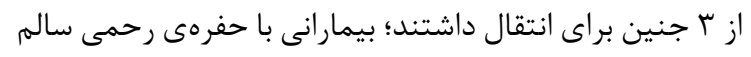

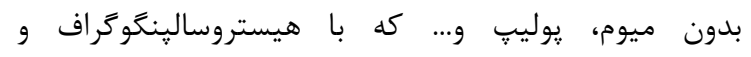

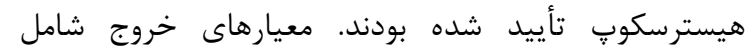

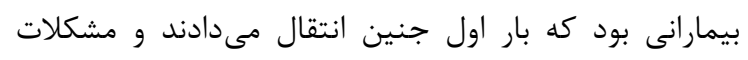

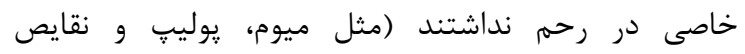
آناتوميكى). (خاصى در

يرسشنامهاى كه شامل سن زن و شوهر، آنائ علت نابارورى،

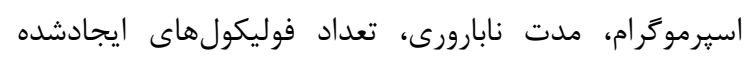

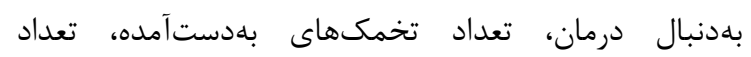
جنينهاى تشكيلشده، تعداد جنينهاى انتقال يافته و نتايج

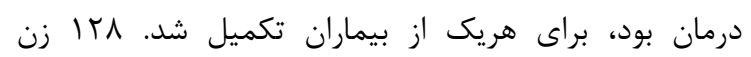

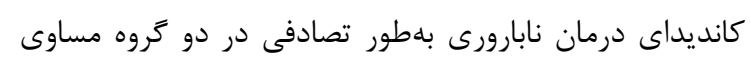

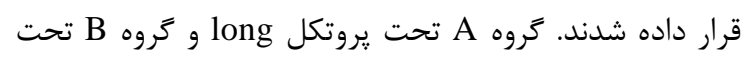
يروتكل استر اديول قرار ترفتند.

\section{بروتكل FET dong (اكونيست GnRH)}

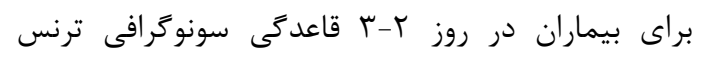

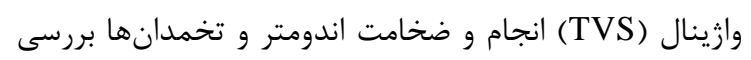

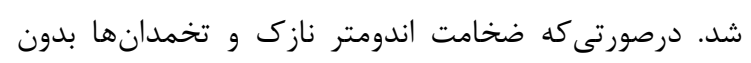

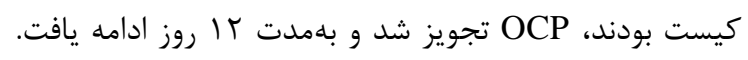

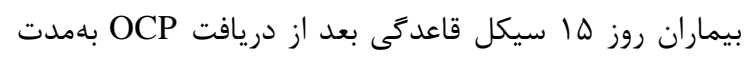

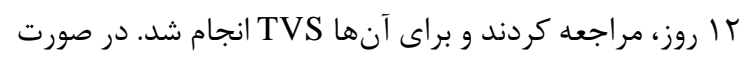

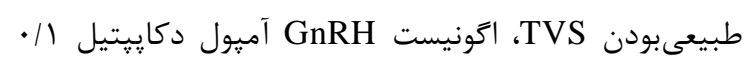

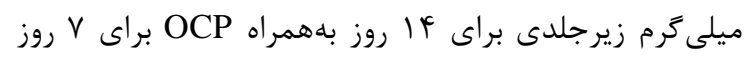

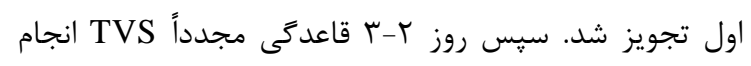

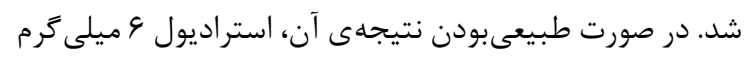

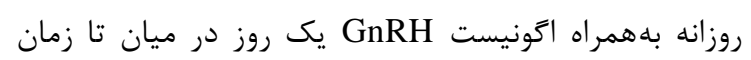

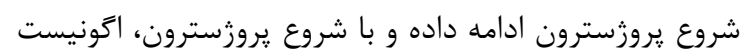

روشهاى لقاح آزمايشآهى مىشود. يكى از اين عوامل سطح

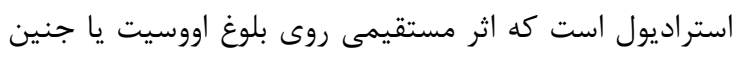

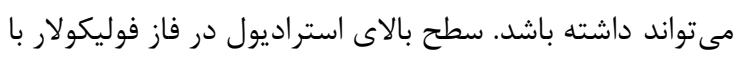

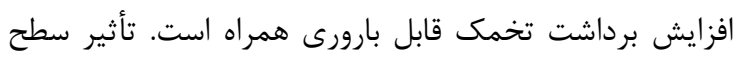

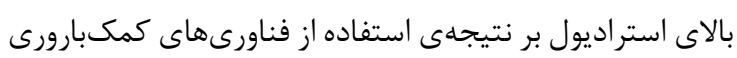

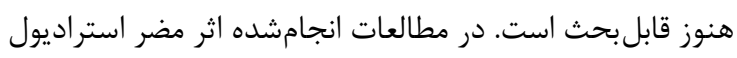

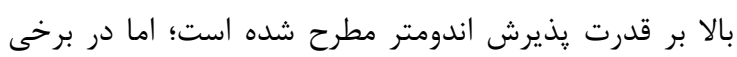

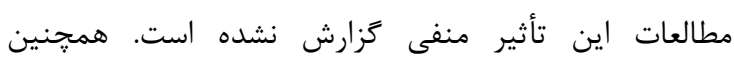

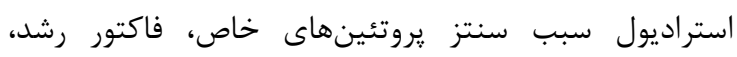

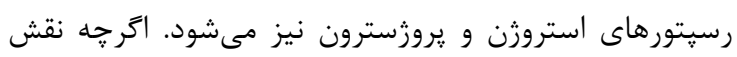

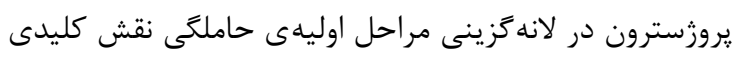

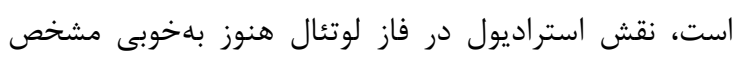

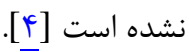

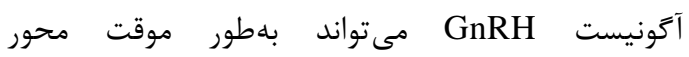

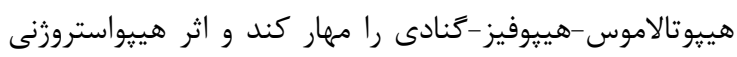

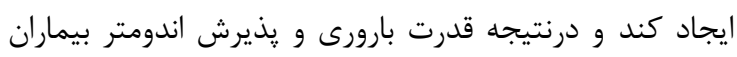

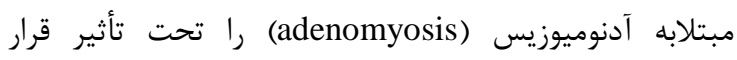

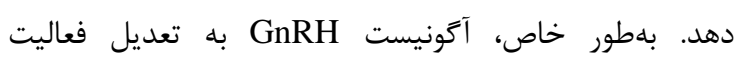
كيرندهاى GnRH (down regulation)

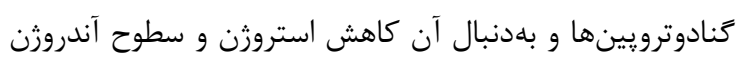
منجر مىشود [ه].

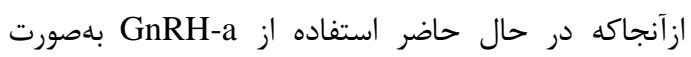

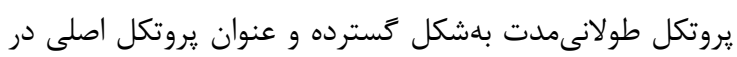

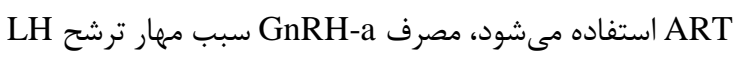

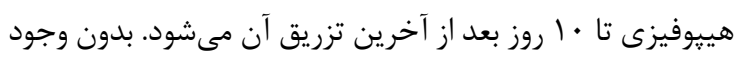

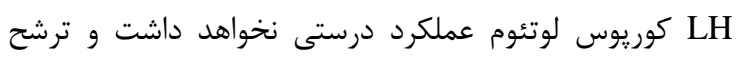

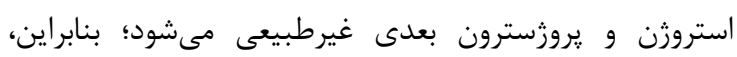

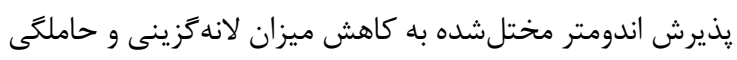

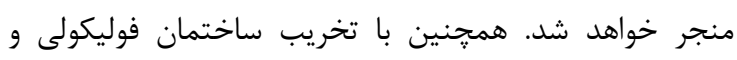

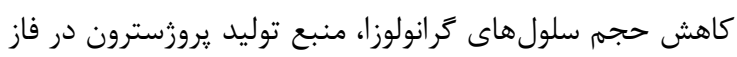

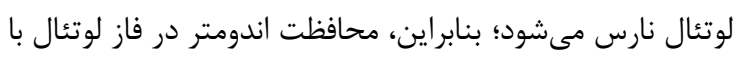

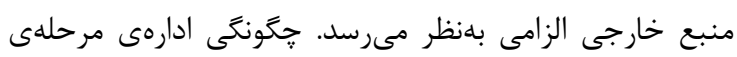

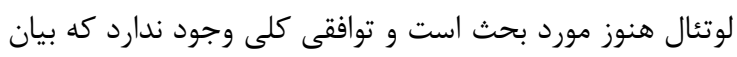

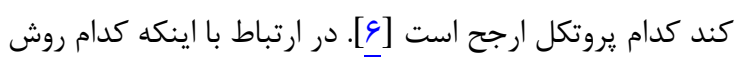

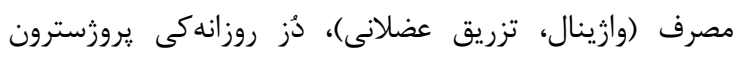

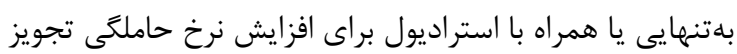

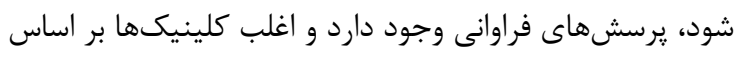

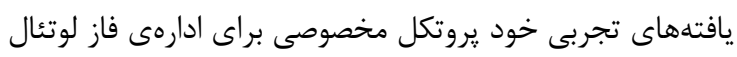

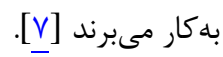

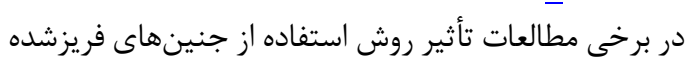

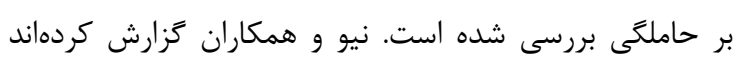

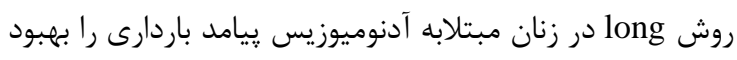

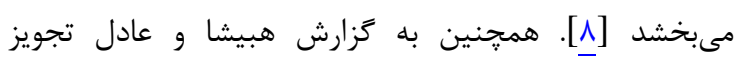

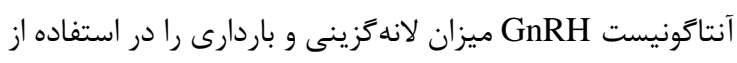


روزهاى بعد . ․ ميلى گرم) و استراديول (نصف دُز مصرفى) و سيس انتقال جنين انجام شد.

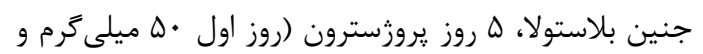

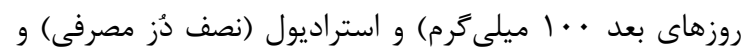

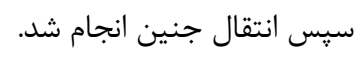

\section{تعريف بيامد}

ييامد حاصل از مطالعه به دو صورت اوليه و ثانويه تعريف شد.

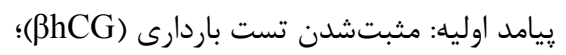

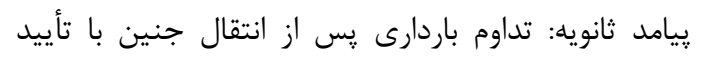
سونو كرافى. تداوم باردارى به ״باردارى با ضربان قلب تشخيص

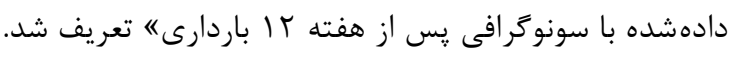

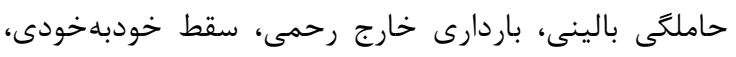

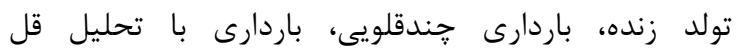

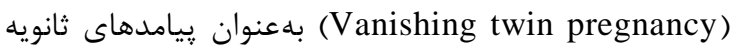

تعريف شدند.

\section{تجزيهوتحليل آمارى}

در اين مطالعه براى تحليل دادهها از نرمافزار SPSS نعارش

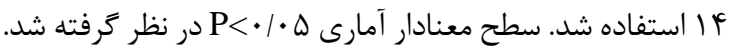

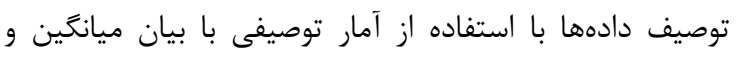

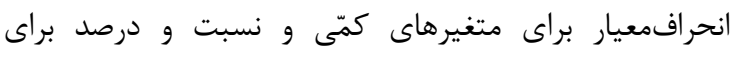
متغيرهاى كيفى انجام شد. براى مقايسهى ارتباط متغيرهاى

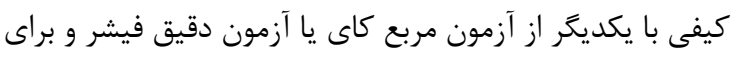

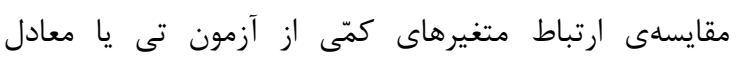

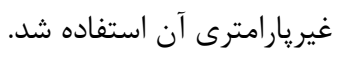

\section{بافته ها}

دو گَروه مطالعهده ازنظر ميانكين سنى، مدت نازايى، نوع

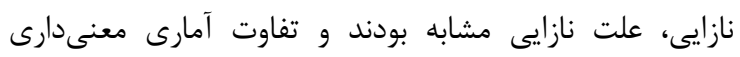
نداشتند (جدول (1).

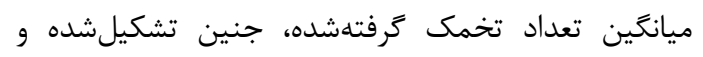

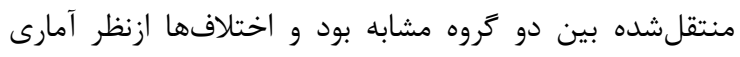

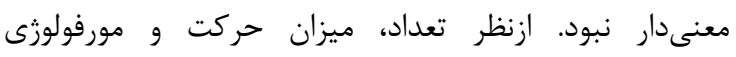

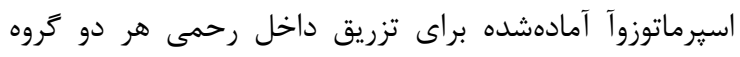

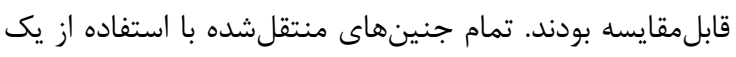
نوع كاتتر منتقل شدند (جدول r).

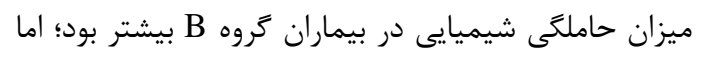

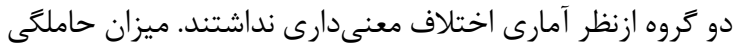

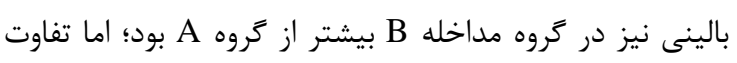
معنى دارى بين دو گروه وجود نداشت (جدول بَ).

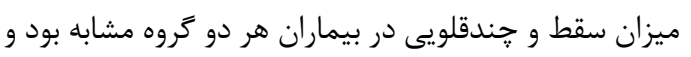
تفاوت آمارى معنى دارى نداشت (جدول ع (أ).

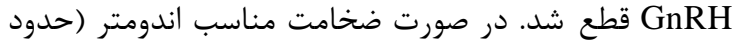

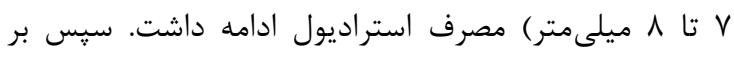
اساس تعداد سلول جنينى يروزسترون شروع و به استراديول

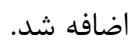

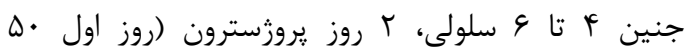
ميلى كرد و سيس انتقال جنين انجام شد.

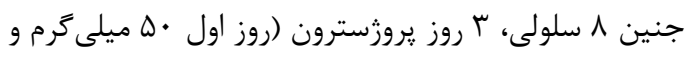

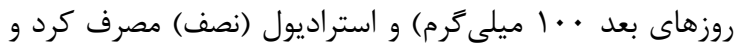
سيس انتقال جنين انجام شد.

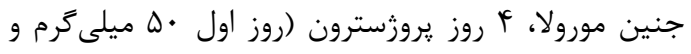

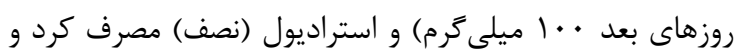
سيس انتقال جنين انجام شد.

جنين بلاستولا، ه روز يروزسترون (روز اول • له ميلى أنرم و روزهاى بعد · ․ ميلى سيس انتقال جنين انجام شد.

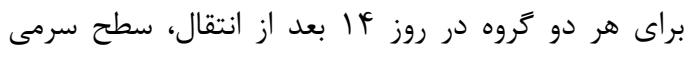

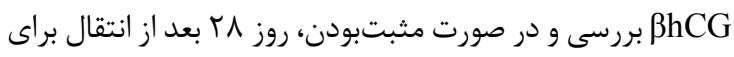

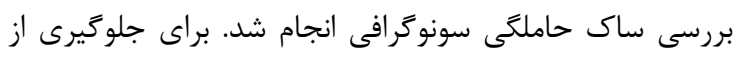

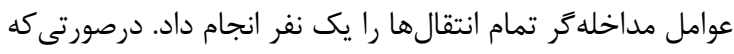
BhCG

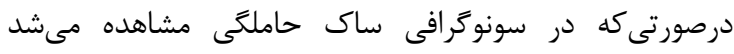

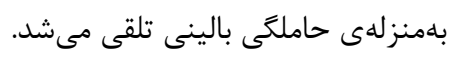

\section{يروتكل استراد يول}

براى بيمار ان در روز Y يا ب قاعدكى TVS انجام شد. ضخامت

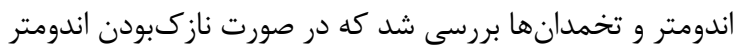

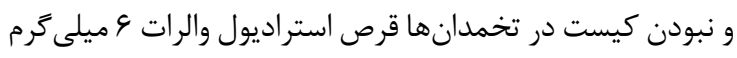

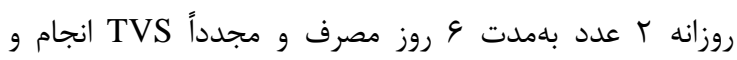

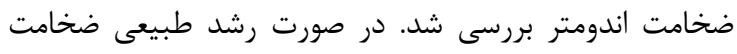

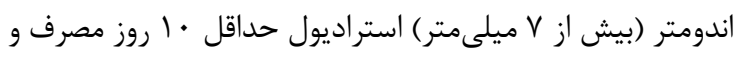

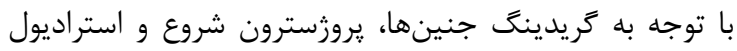
اضافه شد. جنينها بر اساس شكل و كيفيت ظاهرى و مقدار بلاستومرها

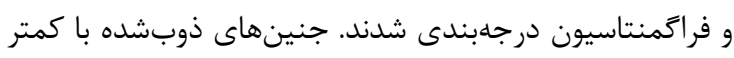

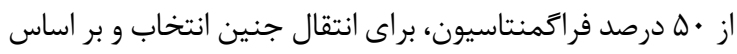

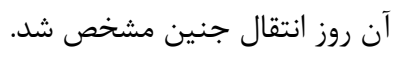

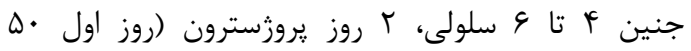
ميلى مصرفى) و سيس انتقال جنين انجام شد.

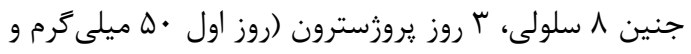

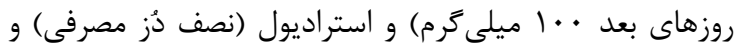
سيس انتقال جنين انجام شد. روزئ

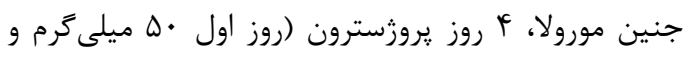


جدول ا: مقايسهى متغيرهاى دموكرافيك و پِايه در دو گروه مطالعهشده

\begin{tabular}{|c|c|c|c|}
\hline $\mathbf{P}$ & 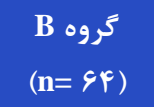 & $\begin{array}{l}A \circ \sigma^{\circ} \\
(n=94)\end{array}$ & \\
\hline$\cdot / 2 \cdot r$ & 要 & $r r / \Lambda \pm \Delta / \Delta$ & سن (سال) ميانگيند انحراف معيار \\
\hline • & $\varepsilon / V \pm F / V$ & $V / \Delta \pm F / V$ & مدت نازايى (سال) ميانگيند انحراف معيار \\
\hline$\cdot / \pi \Delta \Delta$ & $\begin{array}{l}(\varepsilon \wedge / V) F F \\
(r / / T) Y \cdot\end{array}$ & $\begin{array}{l}(\varepsilon \cdot / q) r q \\
(r q / 1) r \Delta\end{array}$ & 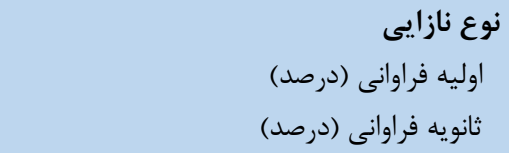 \\
\hline$\cdot 191 \cdot$ & $\begin{array}{l}(Y Y / \Lambda) Y I \\
(Y / Q) \mid Y \\
(Y Y / \Lambda) Y \mid \\
(I T / \Delta) \wedge\end{array}$ & $\begin{array}{l}(Y T / T) Y V \\
(1 Q / 9) I \cdot \\
(T / T) Y \cdot \\
(1 \cdot / 9) V\end{array}$ & 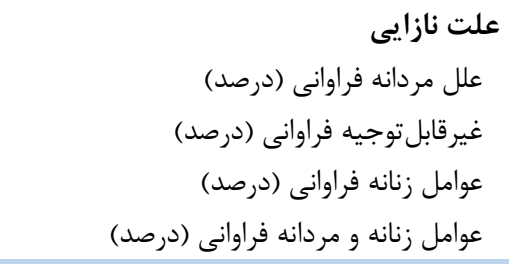 \\
\hline$\cdot 19 \cdot V$ & $\begin{array}{l}(Y \Delta / r) Y q \\
(r q / V) 19 \\
(r \Delta / \cdot) 19\end{array}$ & $\begin{array}{l}(r q / 1) T D \\
(r N / I) \backslash \Lambda \\
(r T / \Lambda) T /\end{array}$ & تحصيلات \\
\hline . $194 q$ & $(\mid \Delta / 9) \mid \cdot$ & $(I N / \mathrm{V}) \mathrm{Ir}$ & سابقه سقط سقط فراوانى (درصد) \\
\hline
\end{tabular}

جدول ז: مقايسهى پارامترهاى مايع منى تلقيحشده براى لقاح رحمى در دو گروه مطالعهشده

\begin{tabular}{|c|c|c|c|}
\hline $\mathbf{P}$ & 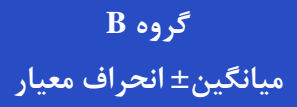 & 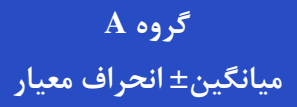 & \\
\hline$\cdot /|\Delta|$ & $\mid r / r \pm q / r$ & $\mid Q / 9 \pm 1 \cdot / r$ & تعداد تخمك \\
\hline .1 .91 & $q / 1 \pm f / V$ & $V / \Delta \pm \Delta / r$ & تعداد جنين \\
\hline $1 / \cdot$ & $r / \Gamma \pm \cdot / \varphi$ & $r / r \pm \cdot / V$ & تعداد جنين منتقل شده \\
\hline$\cdot / 911$ & $r V / \Delta \pm r / V$ & $r V / \Delta \pm F / \cdot$ & 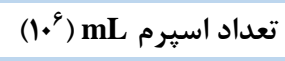 \\
\hline$\cdot / 1 \vee q$ & $\varepsilon r / 9 \pm q / \Lambda$ & $\varphi / / 4 \pm \Delta / \varepsilon$ & مورفولوزى (درصد) \\
\hline . 1114 & $V \cdot / I^{\mathbb{A}} \pm 1 \cdot / \Lambda$ & $\varphi \Delta / 9 \pm r \mid / r$ & مور تاليته (درصد) \\
\hline
\end{tabular}

جدول با: مقايسهى حاملكى آزمايشگاهى و بالينى در دو گروه مطالعهشده

\begin{tabular}{|c|c|c|c|}
\hline $\mathbf{P}$ & $\begin{array}{c}\text { B فراوانى (درصد) } \\
\text { فروه }\end{array}$ & $\begin{array}{c}\text { A كراوانى (درصد) } \\
\text { فروه }\end{array}$ & ييامد \\
\hline$\cdot / r \Lambda$. & $(Y \Psi / F) \backslash D$ & $(I V / T) \|$ & آزمايشگاهى \\
\hline.$/ 4 q$. & r & $(\mid Q / 9) 1$. & بالينى \\
\hline
\end{tabular}

جدول Fا: مقايسهى بيامد حاملكى در بيماران دو گروه مطالعهشده

\begin{tabular}{|c|c|c|c|}
\hline $\mathbf{P}$ & 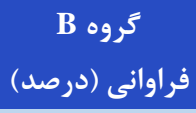 & $\begin{array}{c}\text { A } \mathbf{A} \text { فراوانى (درصد) } \\
\text { فروه }\end{array}$ & بيامد حاملكَى \\
\hline $1 / \cdots$ & $(r / 1) r$ & $(1 / 9) 1$ & سقط \\
\hline- & $(1 / 9) 1$ & $(1 / 9) 1$ & جندقلويى \\
\hline
\end{tabular}

در مقايسه با گروه آكونيست OCP, GnRH بيشتر است. هرجند ازنظر آمارى اين تفاوت معنى دار نبود، ممكن است ازنظر بائن بالينى
يافتههاى مطالعهى حاضر نشان داد ميزان حاملكَى شيميايى

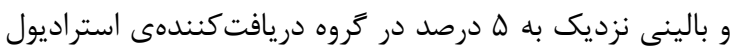


استفاده از فناورىهاى كمكبارورى بحثبرانگيز است. در

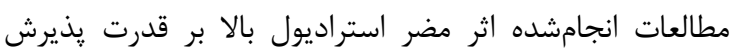

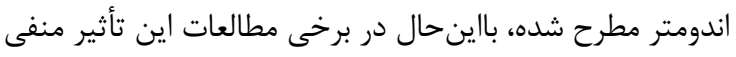

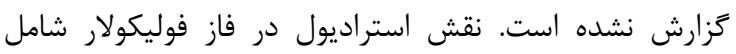

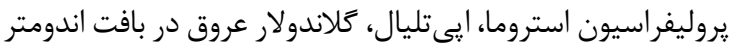

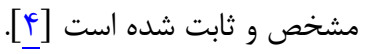

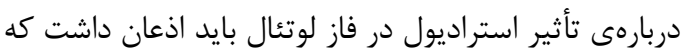

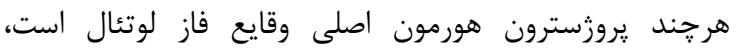

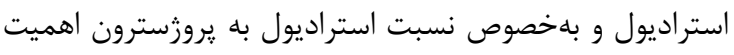

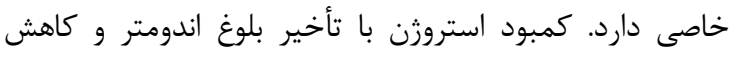

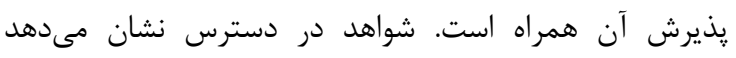

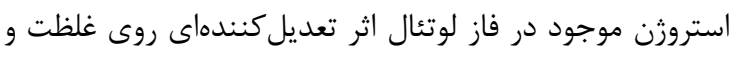

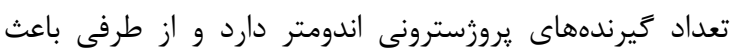
افزايش حساسيت و ياسخدهى آنها مىشود. بعضى از مطالعات

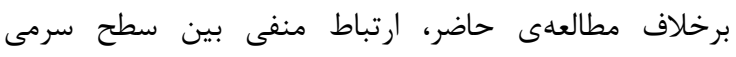

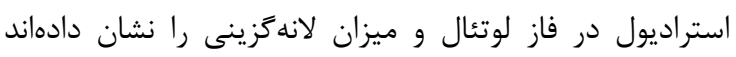

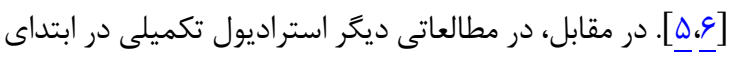

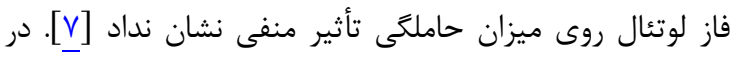

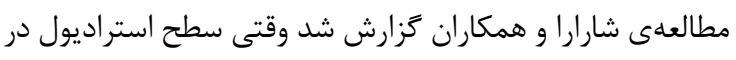

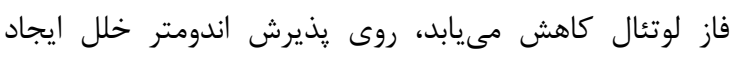

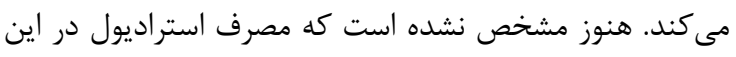

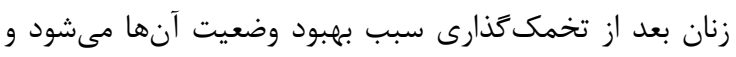

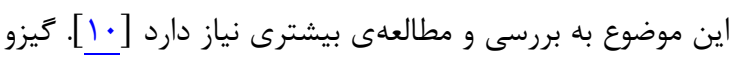

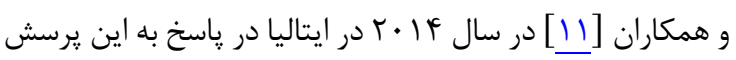

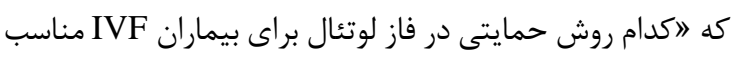

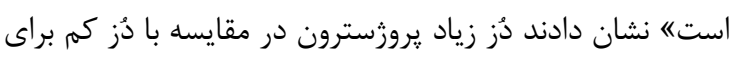

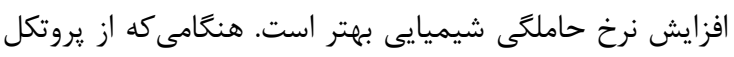

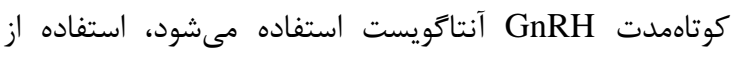

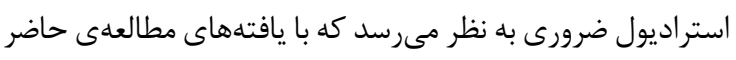
همسو است.

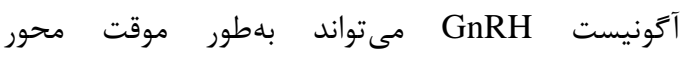

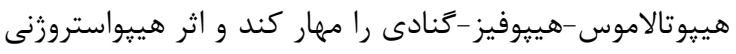
را تحت تأثير قرار دهد. بهطور خاص، آكونيست GnRH به down-regulation حَنادوترويينها و بلهنبال آن كاهش استروزن و سطوح آندروزن

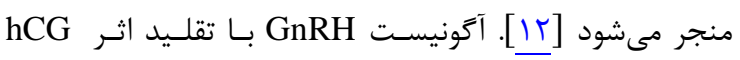

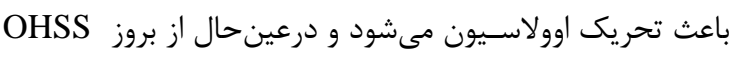

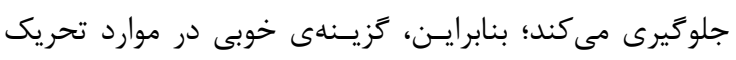

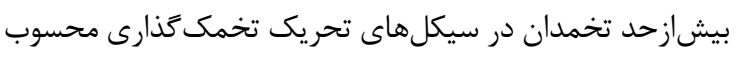
مى شود.

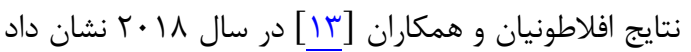

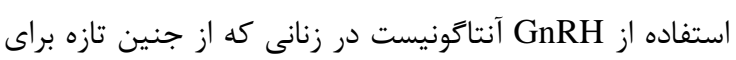

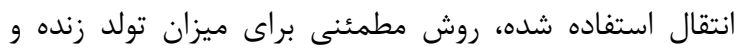

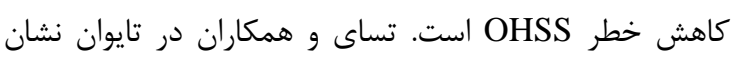

(براى بيماران و يزشكان) اين اختلاف مهمم باشد. در مقابل ميزان

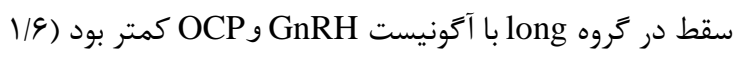

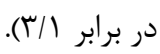
ازآنجاكه هر دو گروه مطالعه ازنظر ميانخين سن، مدت نازايى،

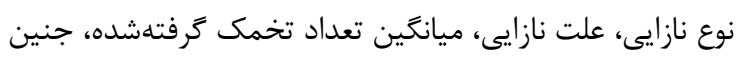

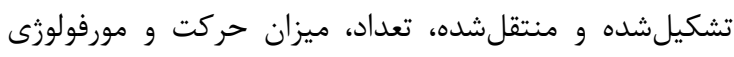

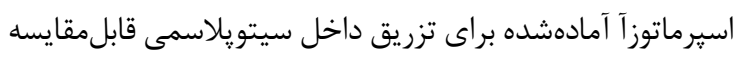

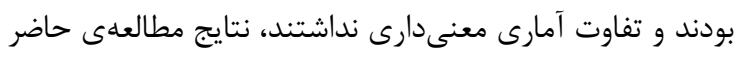

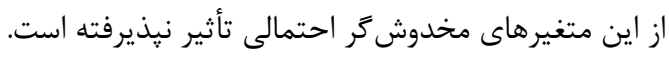

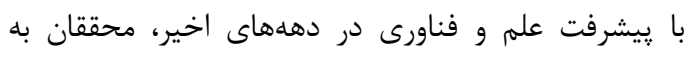

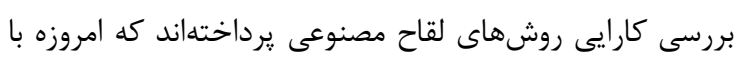

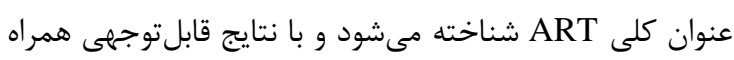

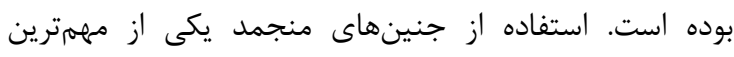

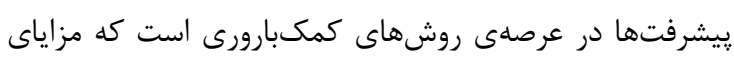

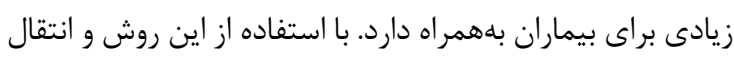

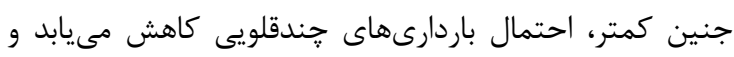

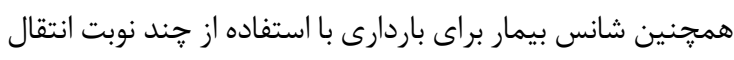

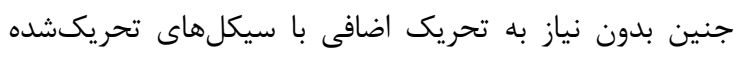

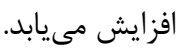
در مطالعهى حاضر كمتر از r درصد از بيمارانى كه حاملكى دانى

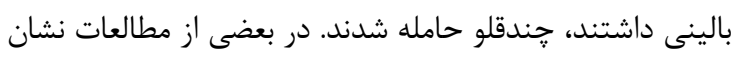

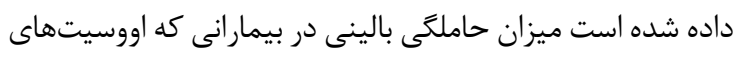

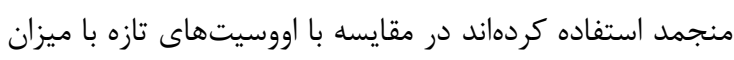

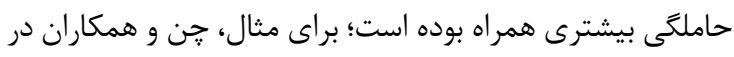

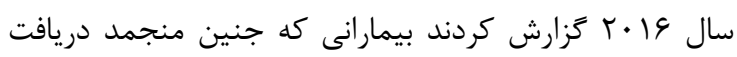

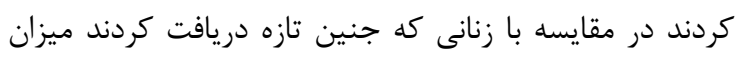

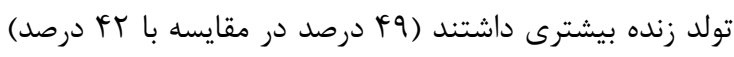

كه اختلاف مشاهدهده ازنظر آمارى معنى دار بود [1].

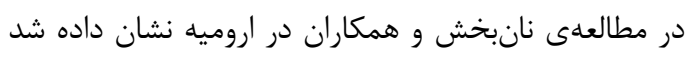

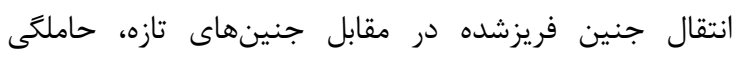

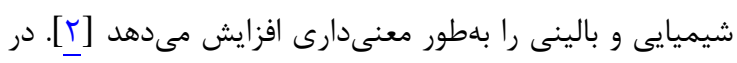

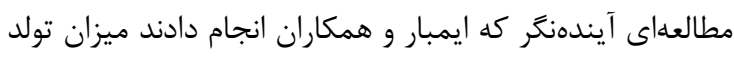

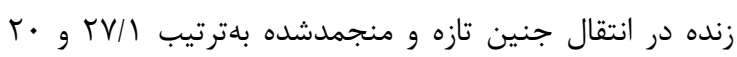

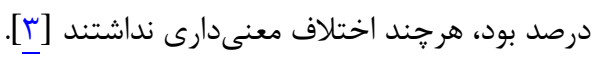

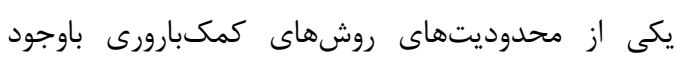

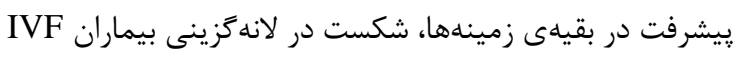

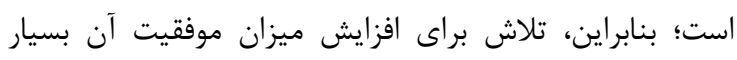

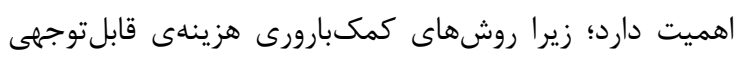

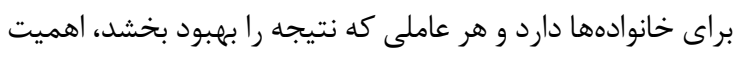

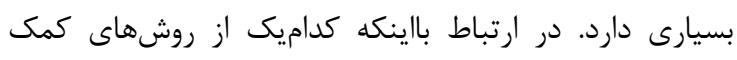

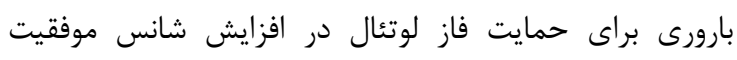
ارجحيت دارد، اختلافنظر وجود دارد و توافق كلى دراينزمينه

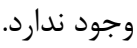
درحالحاضر تأثير سطح بالاى استراديول روى نتيجهى 


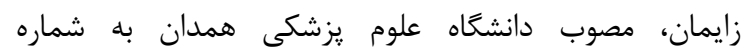

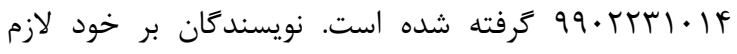
مىدانند از حمايتهاى مادى و معنوى معاونت تحقيقات و فناورى دانشگاه و همكارى بيمارانى كه ما را در انجام اين مطالعه يارى كردند، تشكر و قدردانى كنند.

تضاد منافع نويسندكان اعلام مىدارند كه هيجزَنه تعارض منافعى ندارند.

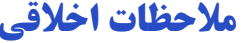

اين مطالعه از كميته اخلاق دانشعاه علوم يزشكى همدان با

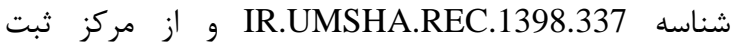
كارآزمايىهاى بالينى كشور با كد

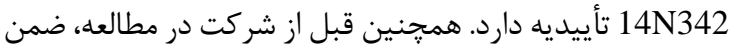
توضيح دربارهى اهداف تحقيق از تمام افراد رضايتنامهى آكاهانهى كتبى كرفته شد.

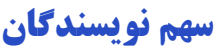

نويسندهى اول (يزوهشكر اصلى): مسئول مكاتبات، طراحى نو

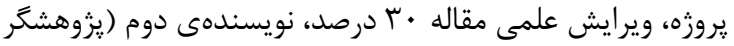

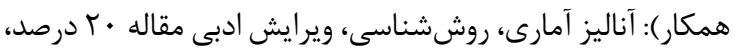

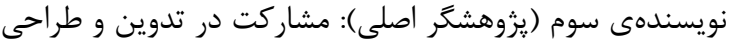

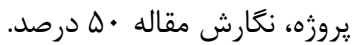

$$
\text { عمايت مالهى }
$$

\section{REFERENCES}

1. Chen ZJ, Shi Y, Sun Y, Zhang B, Liang X, Cao Y, et al. Fresh versus frozen embryos for infertility in the polycystic ovary syndrome. N Engl J Med. 2016;375(6):523-33. PMID: 27509101 DOI: 10.1056/NEJMoa1513873

2. Nananbakhsh F, Ilkhanizadeh B, Moghadasian N. Comparing the outcome of fresh and frozen embryo transfer fertility in infertile women undergoing intracytoplasmic sperm injection. Urmia Med J. 2016;27(5):402-10. [Persian]

3. Imbar T, Kol S, Lossos F, Bdolah Y, Hurwitz A, HaimovKochman R. Reproductive outcome of fresh or frozenthawed embryo transfer is similar in high-risk patients for ovarian hyperstimulation syndrome using GnRH agonist for final oocyte maturation and intensive luteal support. Hum Reprod. 2012;27(3):753-9. PMID: 22252086 DOI: 10.1093/humrep/der463

4. Papageorgiou T, Guibert J, Goffinet F, Patrat C, Fulla Y, Janssens Y, et al. Percentile curves of serum estradiol levels during controlled ovarian stimulation in 905 cycles stimulated with recombinant FSH show that high estradiol is not detrimental to IVF outcome. Hum Reprod. 2002;17(11):2846-50. PMID: 12407037 DOI: 10.1093/ humrep/17.11.2846

5. Forman R, Fries N, Testart J, Belaisch-Allart J, Hazout A, Frydman R. Evidence for an adverse effect of elevated serum estradiol concentrations on embryo implantation. Fertil Steril. 1988;49(1):118-22. PMID: 3335258 DOI:
دادند كاهش اندروزنها بهدنبال استفاده از GnRH ممكن است باعث افزايش شانس حاملگى در زنان با سندرم تخمدان يلى كيستيك شود [ll [l]. البته به اين نكته بايد اشاره كرد كه آتونيست GnRH اثرى لوتئوليز دارد و باعث كوتاهشن فاز لوتئال مىشود كه شايد بتواند كمبودن ميزان حاملكى را در اين مطالعه توجيه كند. آكونيست GnRH بـا تقلـيد اثـر hCG باعث تحريك اوولاسـيون مىشود و درعينحال از بروز OHSS جلوگيرى مى كند؛ بنابرايـن، ززيـنهلى خوبى در موارد تحريك بيشازحد تخمدان در سيكل هاى تحريك تخمك گذارى محسوب مىشود. يروتكل آتونيستهاى GnRH بلندمدت، روشى براى سركوب ترشح گنادوتريينهاى هيبوفيزى درونزاد و درنتيجه ييشخيرى از اولاسيون و فوران زودرس LH درنتيجه حذف اثر آن بر شانس حاملگى است [ها ]. در مطالعهاى يزوهشخران در زنانى كه ياسخ

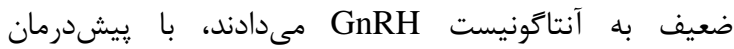
استراديول نتايج مثبتى كزارش كردهاند [ع19]. محققان ديخرى

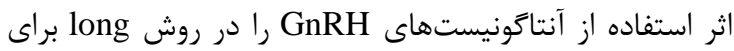
جنينهاى فريزشده بررسى و نتايج قابلمقايسه و اميدبخشى كزارش كردند [IV،

بر اساس يافتههاى مطالعهى حاضر، ميزان باردارى

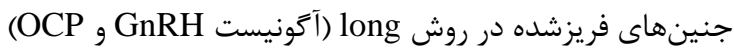
با استراديول تنها روى ييامد حاملتى تفاوت آمارى معنى

\section{تشكر و قدر قاذّى}

اين مقاله از ياياننامهى دكترى تخصصى جراحى زنان و

10.1016/s0015-0282(16)59661-7

6. Smith EM, Anthony FW, Gadd SC, Masson GM. Trial of support treatment with human chorionic gonadotrophin in the luteal phase after treatment with buserelin and human menopausal gonadotrophin in women taking part in an in vitro fertilisation programme. BMJ. 1989;298(6686):14836. PMID: 2503080 DOI: $10.1136 / \mathrm{bmj} .298 .6686 .1483$

7. Fatemi HM. Assessment of the luteal phase in stimulated and substituted cycles. Facts Views Vis Obgyn. 2009; 1(1):30-46. PMID: 25478069

8. Niu Z, Chen Q, Sun Y, Feng Y. Long-term pituitary downregulation before frozen embryo transfer could improve pregnancy outcomes in women with adenomyosis. Gynecol Endocrinol. 2013;29(12):1026-30. PMID: 24006906 DOI: 10.3109/09513590.2013.824960

9. Hebisha SA, Adel HM. GnRH agonist treatment improves implantation and pregnancy rates of frozen-thawed embryos transfer. J Obstet Gynaecol India. 2017;67(2):133-6. PMID: 28405121 DOI: $10.1007 / \mathrm{s} 13224-016-0936-5$

10. Sharara FI, McClamrock HD. Ratio of oestradiol concentration on the day of human chorionic gonadotrophin administration to mid-luteal oestradiol concentration is predictive of in-vitro fertilization outcome. Hum Reprod. 1999;14(11):2777-82. PMID: 10548621 DOI: 10.1093/ humrep/14.11.2777

11. Gizzo S, Andrisani A, Esposito F, Noventa M, Di Gangi S, 
Angioni S, et al. Which luteal phase support is better for each IVF stimulation protocol to achieve the highest pregnancy rate? A superiority randomized clinical trial. Gynecol Endocrinol. 2014;30(12):902-8 PMID: 25268567 DOI: $10.3109 / 09513590.2014 .964638$

12. Mijatovic V, Florijn E, Halim N, Schats R, Hompes P. Adenomyosis has no adverse effects on IVF/ICSI outcomes in women with endometriosis treated with long-term pituitary down-regulation before IVF/ICSI. Eur J Obstet Gynecol Reprod Biol. 2010;151(1):62-5. PMID: 20409633 DOI: 10.1016/j.ejogrb.2010.02.047

13. Aflatoonian A, Mansoori-Torshizi M, Farid Mojtahedi M, Aflatoonian B, Khalili MA, Amir-Arjmand MH, et al. Fresh versus frozen embryo transfer after gonadotropin-releasing hormone agonist trigger in gonadotropin-releasing hormone antagonist cycles among high responder women: A randomized, multi-center study. Int $J$ Reprod Biomed (Yazd). 2018;16(1):9-18. PMID: 29675483

14. Tsai HW, Wang PH, Lin LT, Chen SN, Tsui KH. Using gonadotropin-releasing hormone agonist before frozen embryo transfer may improve ongoing pregnancy rates in hyperandrogenic polycystic ovary syndrome women. Gynecol Endocrinol. 2017;33(9):686-9. PMID: 28393637
DOI: 10.1080/09513590.2017.1307961

15. Wang R, Lin S, Wang Y, Qian W, Zhou L. Comparisons of GnRH antagonist protocol versus GnRH agonist long protocol in patients with normal ovarian reserve: a systematic review and meta-analysis. PLoS One. 2017;12(4):e0175985. PMID: 28437434 DOI: 10.1371/ journal.pone.0175985

16. Sefrioui O, Madkour A, Kaarouch I, Louanjli N. Luteal estradiol pretreatment of poor and normal responders during GnRH antagonist protocol. Gynecol Endocrinol. 2019;35(12):1067-71. PMID: 31142165 DOI: 10.1080/095 $\underline{13590.2019 .1622086}$

17. Khadem Ghaebi N, Mahmoudiniya M, Najaf Najafi M, Zohdi E, Attaran M. Comparison of letrozole with gonadotropin-releasing hormone agonist in frozen embryo transfer after recurrent implantation failure: an RCT. Int $J$ Reprod Biomed (Yazd). 2020;18(2):105-12. PMID: 32259004 DOI: 10.18502/ijrm.v18i2.6417

18. Wong KM, Mastenbroek S, Repping S. Cryopreservation of human embryos and its contribution to in vitro fertilization success rates. Fertil Steril. 2014;102(1):19-26. PMID: 24890275 DOI: $10.1016 /$ j.fertnstert.2014.05.027 